Volume 8, No.3, May - June 2019

International Journal of Advanced Trends in Computer Science and Engineering

Available Online at http://www.warse.org/IJATCSE/static/pdf/file/ijatcse25832019.pdf

https://doi.org/10.30534/ijatcse/2019/25832019

\title{
Novel Design of Full Adders using QCA Approach
}

\author{
R Karthik ${ }^{1}$, K Jyothi ${ }^{2}$ \\ ${ }^{1}$ Department of Electronics and Communication Engineering, MLR Institute of Technology, Hyderabad, India. \\ karthik.r@mlrinstitutions.ac.in \\ ${ }^{2}$ Department of Electronics and Communication Engineering, MLR Institute of Technology, Hyderabad, India.
}

\begin{abstract}
This paper presents a novel design of full adder using QCA approach. It is one of the stand-in technologies introduced as a renewal key to the fundamental limits faced by CMOS technology. Some of the consequences of CMOS technology are their such as high ON/OFF speed, complexity, area and power consumption which are essential to replace with new technology like QCA. By using basic operators like majority gate and an inverter, other logic gates can be designed. Full adders place a major role in computational systems. In this work, 1-bit full adder is mapped out with minimum no. of cells by utilizing cell minimization technique. These circuits are simulated, imitated and verified for their proper output by utilizing QCA designer 2.0.3 tool.
\end{abstract}

Key words: QCA, Quantum Cells, Majority and Minority gate, Inverter, Adder

\section{INTRODUCTION}

QCA is commonly implemented as software programs which are proposed in a year 1993, by Lent et al. It was first fabricated in 1997 (figure 1). QCA does not use transistors. Quantum Cell is the basic cell in QCA. QCA cell is charged with two free electrons. These electrons can reside in exactly two possible sites. Thus, there exist two equivalent arrangements of two electrons in the QCA cell. These two courses of action are signified as cell polarization $\mathrm{p}=+1, \mathrm{p}=$ -1 . Here $\mathrm{p}=+1$ represents logic ' 1 ' and $\mathrm{p}=-1$ represents logic ' 0 '.

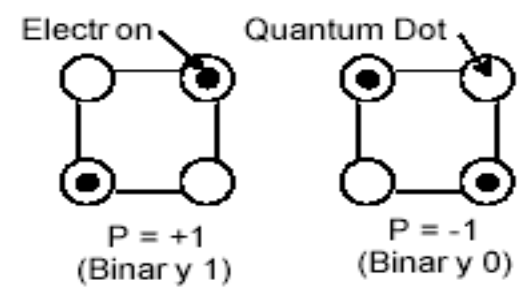

Figure 1: Basic structure of the QCA Cell

\subsection{QCA Fundamentals}

The fundamental basic elements of QCA are an inverter and a majority gate. Detailed description of the major components is presented in the next sections.

\subsection{QCA Majority Gate}

It performs 3 input logic functions (figure 2). The cells on top, at the bottom and at the left works as a resource connection cells.

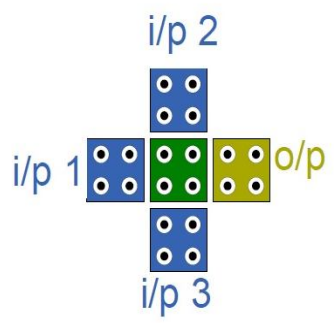

Figure 2: Schematic of the QCA Majority Gate

\subsection{QCA Wire}

A QCA wire is created by arranging no of QCA cells such that large amount of data can be transferred with the high speed (figure 3 ). In this the signal propagates from $\mathrm{i} / \mathrm{p}$ to o/p because of electrostatic association between the cells.

\begin{tabular}{|ll|ll|ll|ll|ll|ll|ll|ll|ll|}
\hline & 0 & 0 & 0 & 0 & 0 & 0 & 0 & 0 & 0 & 0 & 0 & 0 & 0 & 0 & 0 & 0 & 0 \\
0 & 0 & 0 & 0 & 0 & 0 & 0 & 0 & 0 & 0 & 0 & 0 & 0 & 0 & 0 & 0 & 0 & 0 \\
\hline
\end{tabular}

Figure 3: Schematic of the QCA Wire

\subsection{QCA Inverter}

Inverter is a simple structure. It is normally shaped by setting the cells to the corners touching each other. The inversion operation occurs since the quantum dots are misaligned between the cells (figure 4).

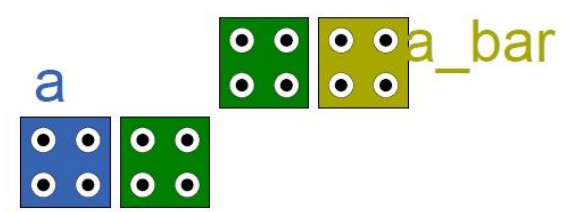

Figure 4: Schematic of the QCA Inverter 


\subsection{QCA Clocking}

In order to propagate the data from QCA wire, the clock zones through the wire must be aligned with consecutive clock signals for the data propagation (figure 5).

\section{\begin{tabular}{lllllllllll|ll|ll|ll|}
$\bullet$ & 0 & 0 & $\bullet$ & 0 & 0 & 0 & 0 & 0 & 0 & 0 & 0 & $\bullet$ & $\bullet$ & $\bullet$ & $\bullet$ \\
0 & 0 & 0 & 0 & 0 & 0 & 0 & 0 & 0 & 0 & 0 & 0 & $\bullet$ & $\bullet$ & $\bullet$ & $\bullet$ \\
\hline
\end{tabular}}

Figure 5: Schematic of Clocking in QCA

\section{BASIC LOGIC GATES}

\subsection{AND GATE}

AND gate can be acquired by keeping the polarization of one of the QCA cell as logic ' 0 ' $(\mathrm{p}=-1)$ in MG. The required equation is $\mathrm{M}(\mathrm{A}, \mathrm{B}, 0)=\mathrm{AB}$ (figure 6$)$.

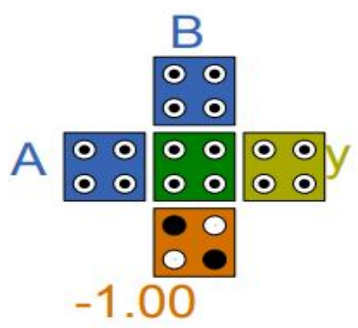

(a)

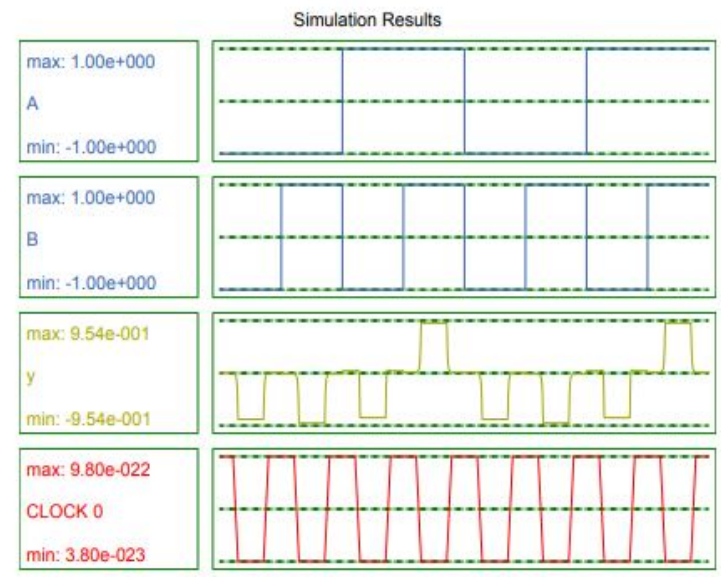

(b)

Figure 6: (a) Basic AND Gate (b) AND gate Simulation

\subsection{OR GATE}

OR gate can be obtained by keeping the polarization of one of the QCA cell as logic ' 1 ' $(\mathrm{p}=1)$ in $\mathrm{MG}$. The required equation is $M(A, B, 1)=A+B$ (figure 7$)$.

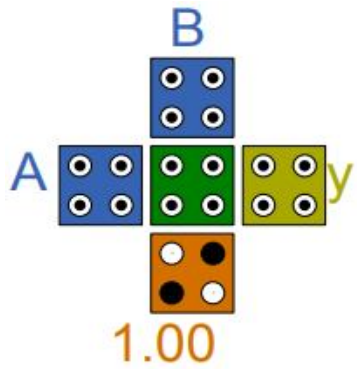

(a)

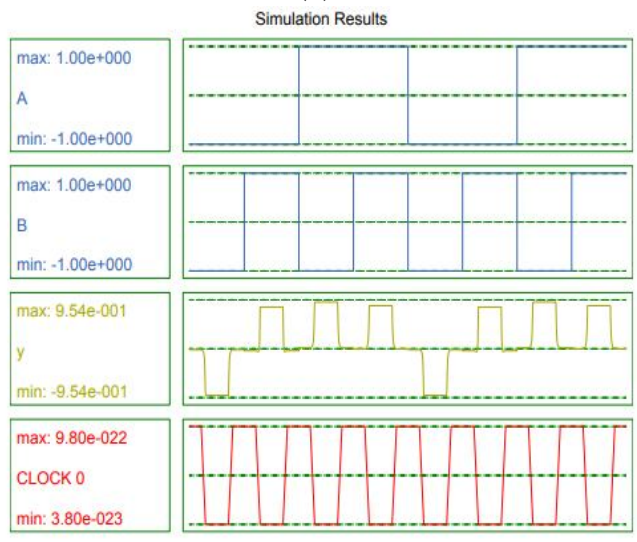

(b)

Figure 7: (a) Basic OR Gate (b) OR gate simulation

\subsection{XOR Gate}

A 3-input $M G$ and an inverter is used to design a 2 input XOR gate. Among the majority gate two AND gates \& one OR gates are used (figure 8).

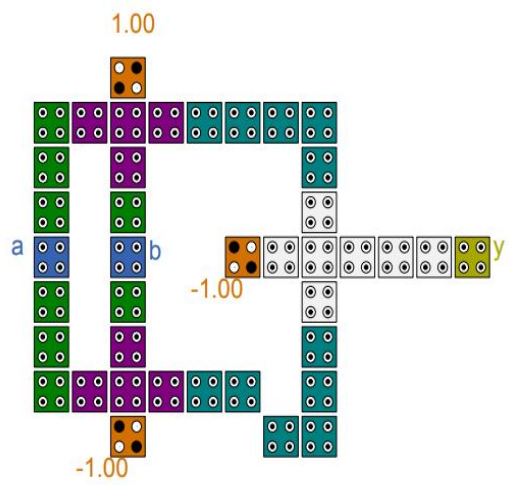

(a) 


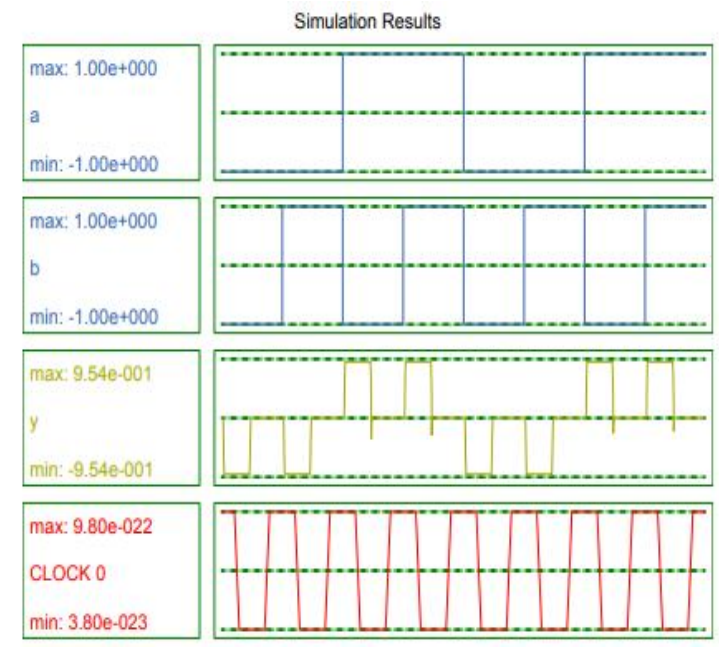

(b)

Figure 8: (a) Basic XOR Gate (b) XOR gate simulation

\section{FULL ADDER}

The Full Adder (FA) design is implemented by utilizing digital logic gates (figure 9). A full adder circuit consists of 3 inputs and 2 outputs. Figure 9 shows the block diagram of full adder. The truth table for full adder is shown in Table 1.

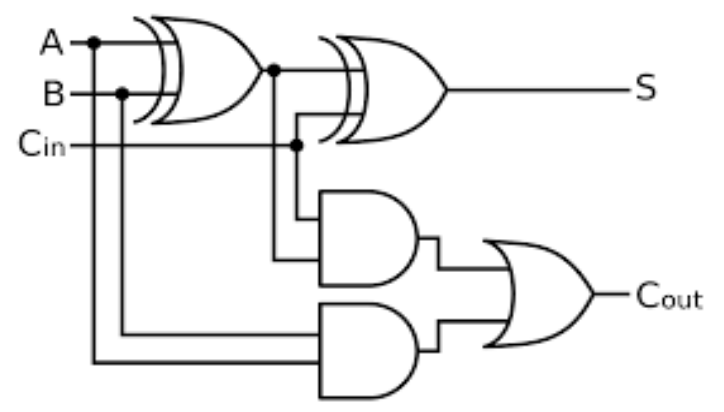

Figure 9: Block diagram of Full Adder

Table 1: 1-bit Full Adder Truth Table

\begin{tabular}{|c|c|c|c|c|}
\hline \multicolumn{3}{|c|}{ Input } & \multicolumn{2}{c|}{ Output } \\
\hline A & B & Cin & Sum & Carry \\
\hline 0 & 0 & 0 & 0 & 0 \\
\hline 0 & 0 & 1 & 1 & 0 \\
\hline 0 & 1 & 0 & 1 & 0 \\
\hline 0 & 1 & 1 & 0 & 1 \\
\hline 1 & 0 & 0 & 1 & 0 \\
\hline 1 & 0 & 1 & 0 & 1 \\
\hline 1 & 1 & 0 & 0 & 1 \\
\hline 1 & 1 & 1 & 1 & 1 \\
\hline
\end{tabular}

The Expression of Full Adder is given as

$$
\begin{aligned}
S U M & =\sum m(1,2,4,7) \\
& =\bar{A} \bar{B} \mathrm{C}+\bar{A} \mathrm{~B} \bar{C}+A \bar{B} \bar{C}+\mathrm{ABC} \\
& =\bar{A}(\bar{B} \mathrm{C}+\mathrm{B} \bar{C})+\mathrm{A}(\bar{B} \bar{C}+\mathrm{BC}) \\
& =\bar{A}(B \oplus C)+A(\overline{B \oplus C}) \\
& =A \oplus B \oplus C \\
C A R R Y= & \sum m(1,2,4,7) \\
= & \bar{A} B \mathrm{C}+A \bar{B} C+A \mathrm{~B} \bar{C}+\mathrm{ABC} \\
= & C(\overline{A B}+\mathrm{A} \bar{B})+\mathrm{AB}(\bar{C}+\mathrm{C}) \\
= & (A \oplus B) C+A B
\end{aligned}
$$

\subsection{Previous design}

QCA adders are implemented by using majority gates and inverter. These are basic building block of QCA circuits. Most of the circuits are designed by using 3 inputs and 5 input majority gates. In this full adder is achieved by using 5 input majority gates.

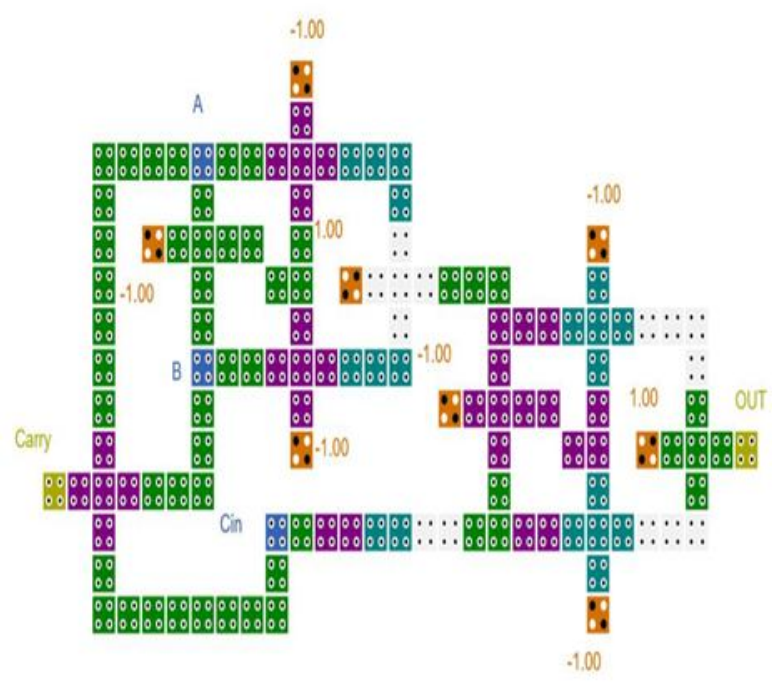

Figure 10: 1-bit Full Adder Previous design

The fundamental basic elements of QCA are an inverter and a majority gate. Detailed description of the major components is

\subsection{Proposed design}

A systematic adder will have a great assistance in designing mathematical circuits. It can be observed that the structures proposed in this work shows that the structures are nearly three times smaller than conventional designs. In this, full adder is blocked out by utilizing 3 input MG and XOR gates(figure 11). 


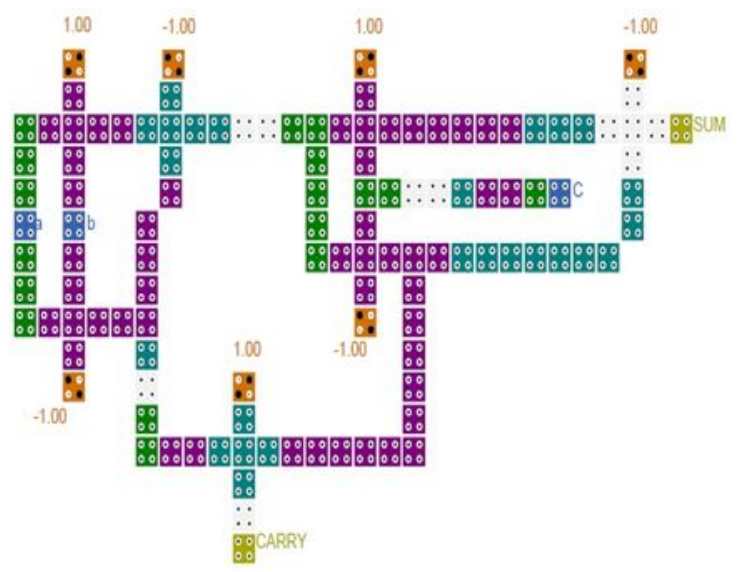

Figure 11: Design of 1-bit Full adder Using QCA Designer Tool

By arranging cells in this way, we get the full adder and the overall number of QCA cells essential to design the FA is 110 total QCA cells with an area of $1980 \mathrm{~nm}^{2}$.

\section{RESULTS AND DISCUSSION}

The circuit functionality and robustness is verified utilizing QCA Designer 2.0.3 tool. QCA Designer is the most popular simulation tool among the scientists worldwide for simulation of QCA based circuit design (figure 12). The present adaptation of QCA Designer has 2 diverse simulation engines included. Comparison of various parameters for full adder design is given in Table 2.

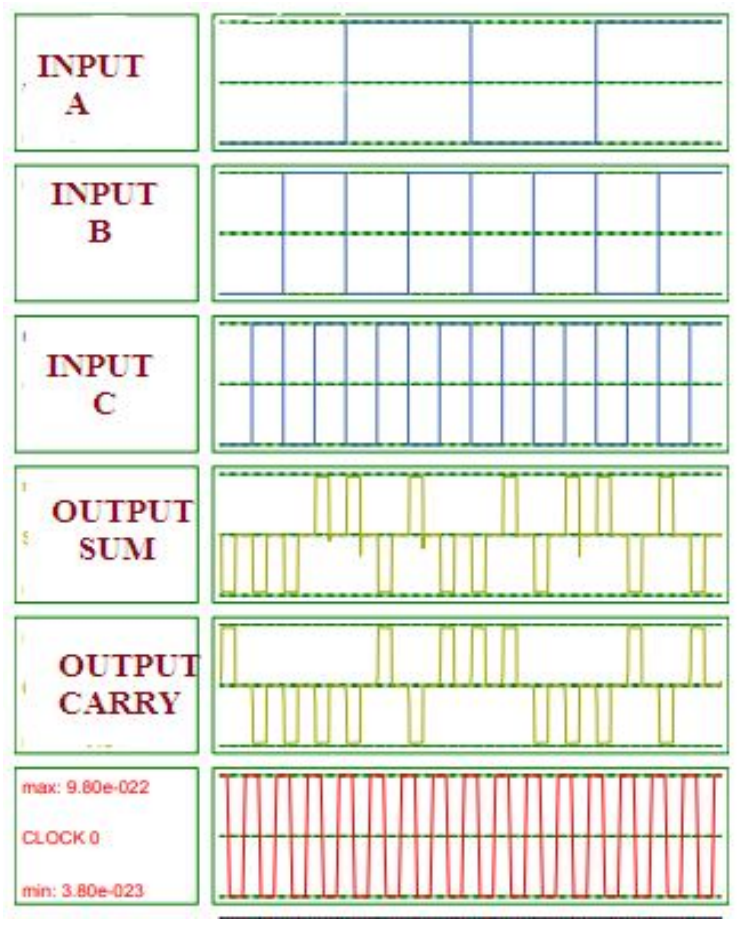

Figure 12: Simulation results of 1-bit adder
Table 2: Results of 1-Bit FA

\begin{tabular}{|c|c|c|}
\hline 1 bit FA & Cell count & Area $\left(\mathrm{nm}^{2}\right)$ \\
\hline Previous [Fig. 10] & 127 & 2230 \\
\hline Previous [6] & 134 & 2550 \\
\hline Proposed [Fig. 11] & 110 & 1980 \\
\hline
\end{tabular}

\section{POWER DISSIPATION IN QCA}

Power dissipation in QCA circuits can be found by QCAPro tool. QCAPro tool is an efficient and powerful tool which finds power dissipation of various types for QCA circuits that have been made utilizing a single layer only [25-29]. One can easily find thermal energy dissipation for QCA design. There will be some hot spots in the thermal model i.e. the black color represents maximum amount of power dissipated and as well as the color goes to while side, it represents the decrease in power dissipation of the circuit itself. Figure 13 and 14 shows the power dissipation results of 1 bit FA. Table 3 shows the Power dissipation analysis of recommended 1-bit FA.

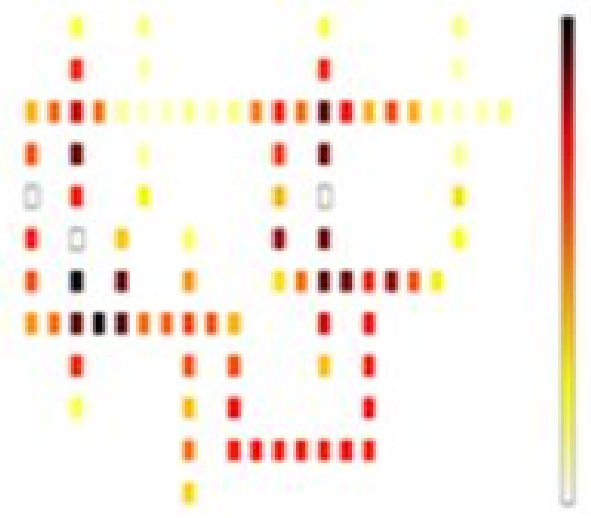

Figure 13: Architecture of the Enhanced Fuzzy Resolution Mechanism using ANFIS

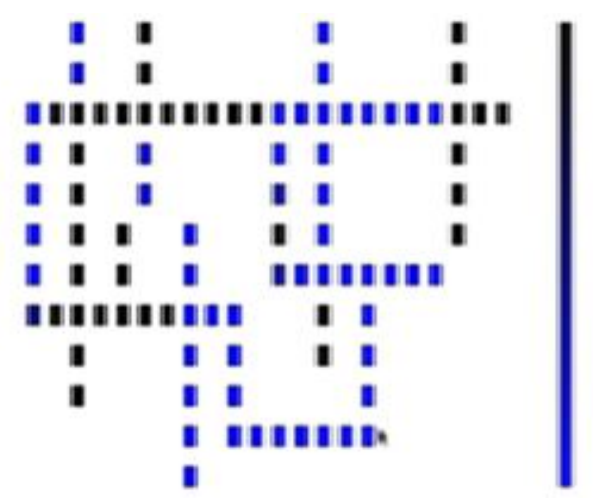

Figure 14: Architecture of the Enhanced Fuzzy Resolution Mechanism using ANFIS 
Table 3: Power dissipation analysis of proposed 1-bit FA

\begin{tabular}{|c|c|c|c|c|c|c|}
\hline \multirow{3}{*}{$\begin{array}{l}\text { Different types of power } \\
\text { dissipation }\end{array}$} & \multicolumn{6}{|c|}{ Kink Eenrgy } \\
\hline & \multicolumn{2}{|c|}{$\mathrm{Ek}=0.5(\mathrm{mev}) \times 10^{-3}$} & \multicolumn{2}{|c|}{$\mathrm{Ek}=1(\mathrm{mev}) \times 10^{-3}$} & \multicolumn{2}{|c|}{$\mathrm{Ek}=1.5(\mathrm{mev}) \times 10^{-3}$} \\
\hline & $\begin{array}{c}\text { Previous } \\
\text { Design }\end{array}$ & $\begin{array}{c}\text { Proposed } \\
\text { Design }\end{array}$ & $\begin{array}{c}\text { Previous } \\
\text { Design }\end{array}$ & $\begin{array}{c}\text { Proposed } \\
\text { Design }\end{array}$ & $\begin{array}{c}\text { Previous } \\
\text { Design }\end{array}$ & $\begin{array}{r}\text { Proposec } \\
\text { Design }\end{array}$ \\
\hline $\begin{array}{c}\text { Maximum Energy dissipation of } \\
\text { circuit }\end{array}$ & 0.318 & 0.297 & 0.382 & 0.317 & 0.425 & 0.350 \\
\hline $\begin{array}{c}\text { Avgerage Energy dissipation of } \\
\text { circuit }\end{array}$ & 0.264 & 0.150 & 0.264 & 0.190 & 0.356 & 0.241 \\
\hline $\begin{array}{c}\text { Minimum Energy dissipation of } \\
\text { circuit }\end{array}$ & 0.034 & 0.026 & 0.095 & 0.081 & 0.248 & 0.146 \\
\hline Average Leakage Dissipation & 0.029 & 0.027 & 0.095 & 0.083 & 0.263 & 0.149 \\
\hline $\begin{array}{c}\text { Average Switching Energy } \\
\text { Dissipation }\end{array}$ & 0.248 & 0.173 & 0.159 & 0.107 & 0.296 & 0.134 \\
\hline
\end{tabular}

\section{CONCLUSION}

QCA is a new technology developing to design Quantum computing devices. This methodology is an efficient way that reduces number of cells, area and delay in signal propagation from input to output. From the proposed full adder designs, one can easily compare the designs with reported designs for power dissipation, area, total no of cell counts. The proposed designs are robust and efficient than the previous designs.

\section{REFERENCES}

1. C. S. Lent, P. D. Tougaw, W. Porod, G. H. Bernstein, "Quantum cellular automata", Nanotechnology, vol. 4, no. $\quad 1, \quad$ pp. 1993. https://doi.org/10.1088/0957-4484/4/1/004

2. J.C. Jeon, "Extendable QCA decoding architecture architecture using 5 input majority gate", International Journal of Control and Automation, vol. 8, no. 12, pp. 107-118,

2015. https://doi.org/10.14257/ijca.2015.8.12.10

3. H. Cho, E. E. Swartzlander, "Adder and multiplier design in Quantum-dot Cellular Automata", IEEE Trans. Comput, vol. 58, no. 6, pp. 721-727, 2009. https://doi.org/10.1109/TC.2009.21

4. R. Zang, K. Walus, W. Wang, G. A. Jullien, "A method of majority logic reduction for quantum cellular automata", IEEE Trans, nanotechnology, vol. 3, pp. 443-450,

2004. https://doi.org/10.1109/TNANO.2004.834177

5. T. R Devi, "Implementation of adder by using QCA technology", 1993

6. Kondwani Makanda and Jun-Cheol Jeon, "Combinational Circuit Design Based on Quantum-Dot Cellular Automata", International Journal of Control and Automation, Vol. 7, No. 6, pp. 369-378, Jun. 2014. https://doi.org/10.14257/ijca.2014.7.6.34
7. O. Snider, I Amlani, Bernstein, C. S. Lent, J. L. Merz, W. Porod, "A functional cell for quantum dot cellular automata, Solid-State Electron ",vol. 42, pp. 1355-1359, 1998. https://doi.org/10.1016/S0038-1101(98)00030-6

8. J. C. Jeon, "Low hardware complexity QCA decoding architecture using inverter chain", International Journal of Control and Automation, vol. 9, no. 4, pp. 347-358, 2016. https://doi.org/10.14257/ijca.2016.9.4.34

9. S. E. Frost, T. J. Dysart, P. M. Kogge, and C. S. Lent, "Carbon nano-tubes for quantum-dot cellular automata clocking”, IEEE Conference on Nanotechnology, vol. 171, August 2004.

10. P. D. Toudaw and C. S. Lent, "Logical device implemented using quantum cellular automata", Journal of Applied physics, vol. 75, no. 3, (1994), pp. 1818-1825. https://doi.org/10.1063/1.356375.

11. K. Walus, G. Schulhof, and G. A. Jullien, "High level exploration of quantum-dot cellular automata (QCA)," in Proceedings of the 38th Asilomar Conference on Signals, Systems and Computers, vol. 1, pp. 30-33, IEEE, November 2004.

12. A. Gin, P. D. Tougaw, and S. Williams, "An alternative geometry for quantum-dot cellular automata," Journal of Applied Physics, vol. 85, no. 12, pp. 8281-8286, 1999. https://doi.org/10.1063/1.370670

13. G. Schulhof, K. Walus, and G. A. Jullien, "Simulation of random cell displacements in QCA," ACM Journal on Emerging Technologies in Computing Systems, vol. 3, no. 1, p. 2, 2007. https://doi.org/10.1145/1229175.1229177

14. I. L. Bajec and P. Pecar, "Two-layer synchronized ternary quantum-dot cellular automata wire crossings," Nanotechnology, vol. 7, pp. 368-376, 2012. https://doi.org/10.1186/1556-276X-7-221

15. R. Zhang, K. Walus, W. Wang, and G. A. Jullien, "A method of majority logic reduction for quantum cellular automata," IEEE Transactions on Nanotechnology, vol. 3, no. 4, pp. 443-450, 2004. https://doi.org/10.1109/TNANO.2004.834177

16. H. Cho and E. E. Swartzlander, "Adder designs and analyses for quantum-dot cellular automata," IEEE Transactions on Nanotechnology, vol. 6, no. 3, pp. 374-383, 2007. https://doi.org/10.1109/TNANO.2007.894839

17. S. Hashemi, M. Tehrani, and K. Navi, "An efficient quantum-dot cellular automata full-adder," Scientific Research and Essays, vol. 7, no. 2, pp. 177-189, 2012.

18. K. Walus, T. J. Dysart, G. A. Jullien, and R. A. Budiman, "QCADesigner: a rapid design and simulation tool for quantum-dot cellular automata," IEEE Transactions on Nanotechnology, vol. 3, no. 1, pp. 26-31, 2004. https://doi.org/10.1109/TNANO.2003.820815

19. V. Vankamamidi, M. Ottavi, and F. Lombardi, "Clocking and cell placement for QCA," in Proceedings of the 6th IEEE Conference on Nanotechnology (IEEE-NANO '06), vol. 1, pp. 343-346, June 2006. https://doi.org/10.1109/NANO.2006.247647 
20. Z. D. Patitz, N. Park, M. Choi, and F. J. Meyer, "QCA-based majority gate design under radius of effect-induced faults," in Proceedings of the 20th IEEE International Symposium on Defect and Fault Tolerance in VLSI Systems (DFT '05), pp. 217-225, IEEE, October 2005.

21. W. Wang, K. Walus, and G. A. Jullien, "Quantum-dot cellular automata adders," in Proceedings of the 3rd IEEE Conference on Nanotechnology, pp. 461-464, 2003.

22. M. R. Azghadi, O. Kavehei, and K. Navi, "A novel design for quantum-dot cellular automata cells and full adders," Journal of Applied Sciences, vol. 7, no. 22, pp. 3460-3468, 2007. https://doi.org/10.3923/jas.2007.3460.3468

23. S. Sayedsalehi, M. H. Moaiyeri, and K. Navi, "Novel efficient adder circuits for quantum-dot cellular automata," Journal of Computational and Theoretical Nanoscience, vol. 8, no. 9, pp. 1769-1775, 2011. https://doi.org/10.1166/jctn.2011.1881

24. V. Pudi and K. Sridharan, "Low complexity design of ripple carry and brent-kung adders in QCA," IEEE Transactions on Nanotechnology, vol. 11, no. 1, pp. 105-119, 2012. https://doi.org/10.1109/TNANO.2011.2158006

25. M. Momenzadeh, M. Ottavi, and F. Lombardi, "Modeling QCA defects at molecular-level in combinational circuits," in Proceedings of the 20th IEEE International Symposium on Defect and Fault Tolerance in VLSI Systems (DFT '05), pp. 208-216, October 2005.

26. Sankit R Kassa, R K Nagaria, R Karthik, "Energy efficient neoteric design of a 3-input Majority Gate with its implementation and physical proof in Quantum dot Cellular Automata", Nano Communication Networks (Elsevier), Vol 15, pp. 28-40, (2018).

https://doi.org/10.1016/j.nancom.2018.02.001

27. Karthik R, Kassa S R, "Implementation of flip flops using QCA tool", Journal of Fundamental and Applied Sciences, Vol. 10, Issue 6S, pp. 2332-2341, (2018).

28. Ch.Rajesh Babu, T Venkatesh, E Jagadeeshwara Rao and U V Raju, "Conventional Full Adder FinFET Implementation using Transmission Gate logic", Vol. 7, No. 6, International Journal of Advanced Trends in Computer Science and Engineering, 2018. https://doi.org/10.30534/ijatcse/2018/11762018

29. P.Sowndarya Mala, N.M.Ramalingeswara Rao, V.Sreevani and M.Sai, "Analysis and Reduction of high power consumption using parallel prefix adder", Vol. 7, No. 6, International Journal of Advanced Trends in Computer Science and Engineering, 2018. https://doi.org/10.30534/ijatcse/2018/21762018 